\section{EL PERÚ PROFUNDO}

\author{
DETEOFILOHINOSTROZA
}

\section{- luis cáceres álvarez}

https://orcid.org/0000-0002-1738-5483

Periodista y docente de la Universidad

Peruana de Ciencias Aplicadas - UPC

pcculcac@upc.edu.pe

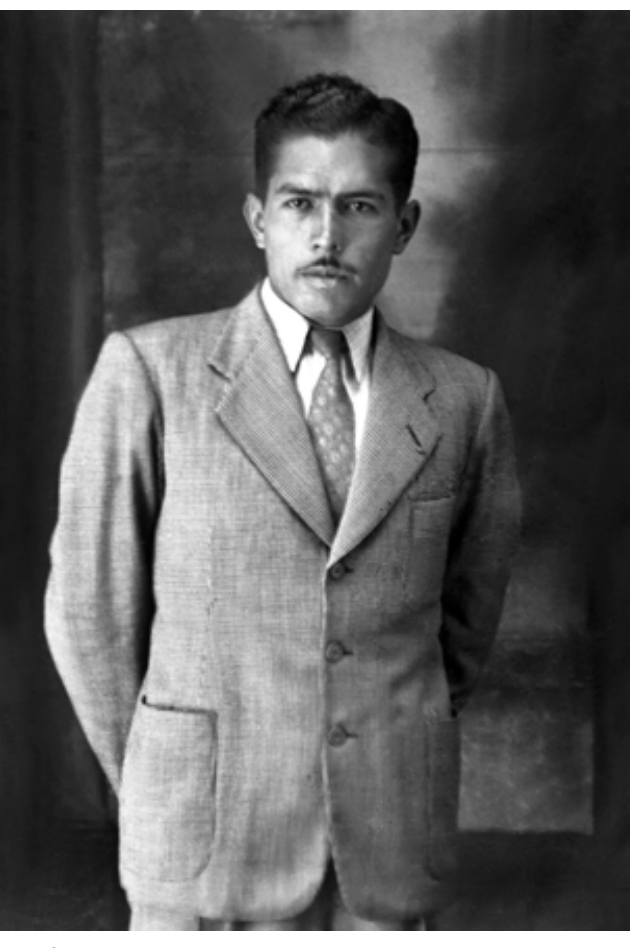

Teófilo Hinostroza. Autorretrato, 1945.

na mujer hilando en las alturas de Huancavelica carga a un bebe en su espalda, quien observa directamente la lente de Teófilo Hinostroz (Colcabamba, 1914 - Huancayo, 1991), como asomándose con cierta curiosidad. La mujer sigue su camino mientras el fotógrafo elogia la ternura del Ande y la contemplación de lo cotidiano contenido en aquel breve encuentro. Toda su obra respira la frescura de la vida a su alrededor $y$, al mismo tiempo, encierra la mística del mundo andino.

Se dice de él que era "el Chambi del Centro" por el testimonio visual de cinco décadas de las costumbres y los paisajes de las comunidades de la sierra central de nuestro país gracias a su dominio del quechua, la impecable composición y la espontaneidad que marca su obra. Pero, seguimos sin tener en la memoria a un fotógrafo que amaba el simple sonido de una quena y al que, en 1975, las cámaras de la $\mathrm{BBC}$ de Londres mostraron como un prodigio. Aquél fotógrafo, fue un artista muy apreciado por José María Arguedas, con quien compartió largas horas en el centro cultural que fundó en el

4 Arado. Colcobamba, 1958 segundo piso de su estudio fotográfico "Foto El Arte" en Huancayo, entre 1937 y 1985 . ¿Cómo es posible no reconocer en vida esa obra?

Servais Thissen es un investigador belga que llegó al Perú hace más de cincuenta años. Desde el primer momento se interesó por la historia de la fotografía, así como por el trabajo de diversos intelectuales peruanos de inicios del siglo XX. Estos intereses lo llevaron a estudiar la obra de Martín Chambi y, posteriormente, decidió realizar un registro de los fotógrafos peruanos. Fue debido a esto que llegó, casi de casualidad, a conocer la obra de Hinostroza.

Hace más de una década, Servais conoció en Huancayo a Zoila, hija de Teófilo, quien le comentó entristecida que la obra de su padre había caído en el olvido y le pidió ayuda para defenderla de la indiferencia. El investigador quedó impresionado por los paisajes del valle del Mantaro en un archivo que consta de 5000 negativos, algunos de $6 \times 6 \mathrm{~cm}$, otros de $6 \times$ $9 \mathrm{~cm}$, e incluso de algunas placas de vidrio en buen estado.

"Tiene gran valor antropológico, muy buen manejo de la composición, del encuadre, sentido de la estética y conocimiento del lenguaje. Es un buen complemento de Chambi, quien solo recorrió el sur del Perú", afirma Thissen.

Aunque Hinostroza no figuró en ningún registro de fotografía del país hasta la vista paciente de Servais, hay material hasta los inicios de los ochenta, pero ninguna imagen miserable o de violencia terrorista en su gran archivo, dice. Para él, Teófilo no pretendió dejar de lado la pobreza o las revueltas sociales de ese entonces, sino que escogió rescatar la belleza para que resuene siempre y demostrar que el Perú es más grande que esas grietas. "Un legado digno de conocerse", enfatiza. Mientras que en sus cartas queda la frase: "Hay que captar las imágenes del Perú profundo".

Este último término fue acuñado por el historiador Jorge Basadre quien, en 1947, describió la existencia de una parte del país en el que, hasta ahora, reposa una promesa de 
futuro. Es complicado, pero necesario el debate. Hemos tenido muchísmos grados de desconocimiento de lo que somos como perus no mostrarlo, o al no enterar ciamos del lugar en el que vivimos. Entonces, urge conocernos. Basta mirar su archivo, a sus personajes en los días de faena, los ritos de siembra y de cosecha, las fiestas alegóricas y los imponentes paisajes andinos. Maestría evidencia y comprensión son los valores que tenemos a través de la sobriedad de la luz de la sierra central en el registro de Hinostroza.

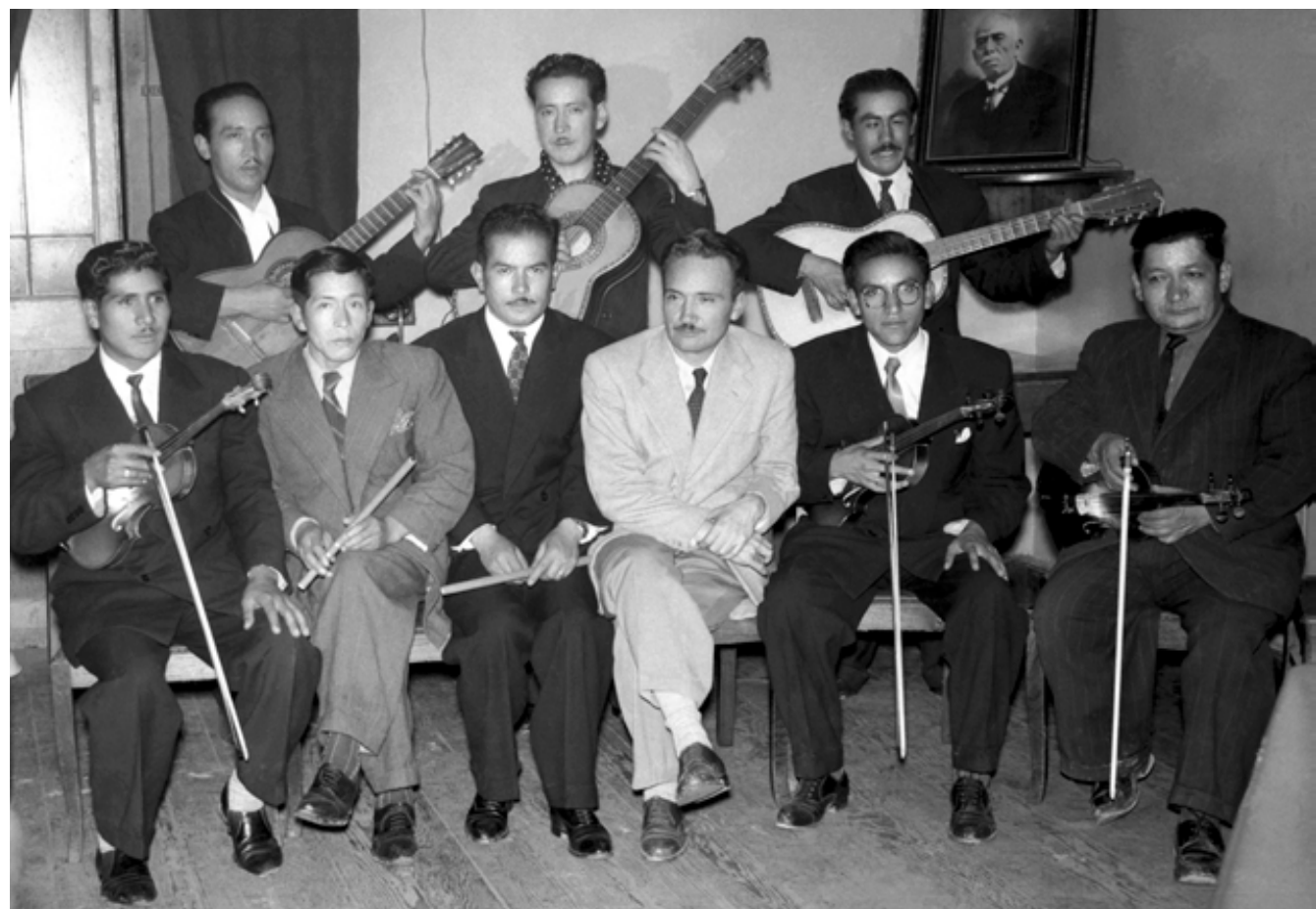

Centro Musical. José María Arguedas (de terno claro) y Teófilo Hinostroza a su derecha (con quena). Huancayo, 1954.
Regresemos a la fotografía de portada del libro El Perú profundo (2008), publicado por Thissen. La imagen se titula Alturas de Colcabamba, 1958. Una joven madre teje los sueños que tiene con su bebé a cuestas. Le da vueltas al hilo con delicadeza e inquebrantable perseverancia, como queriendo ensañarnos alguna lección Su presencia domina las montapaso firme. La fotografía en el Perú, en muchos sentidos, es aún un mundo por descubrir.

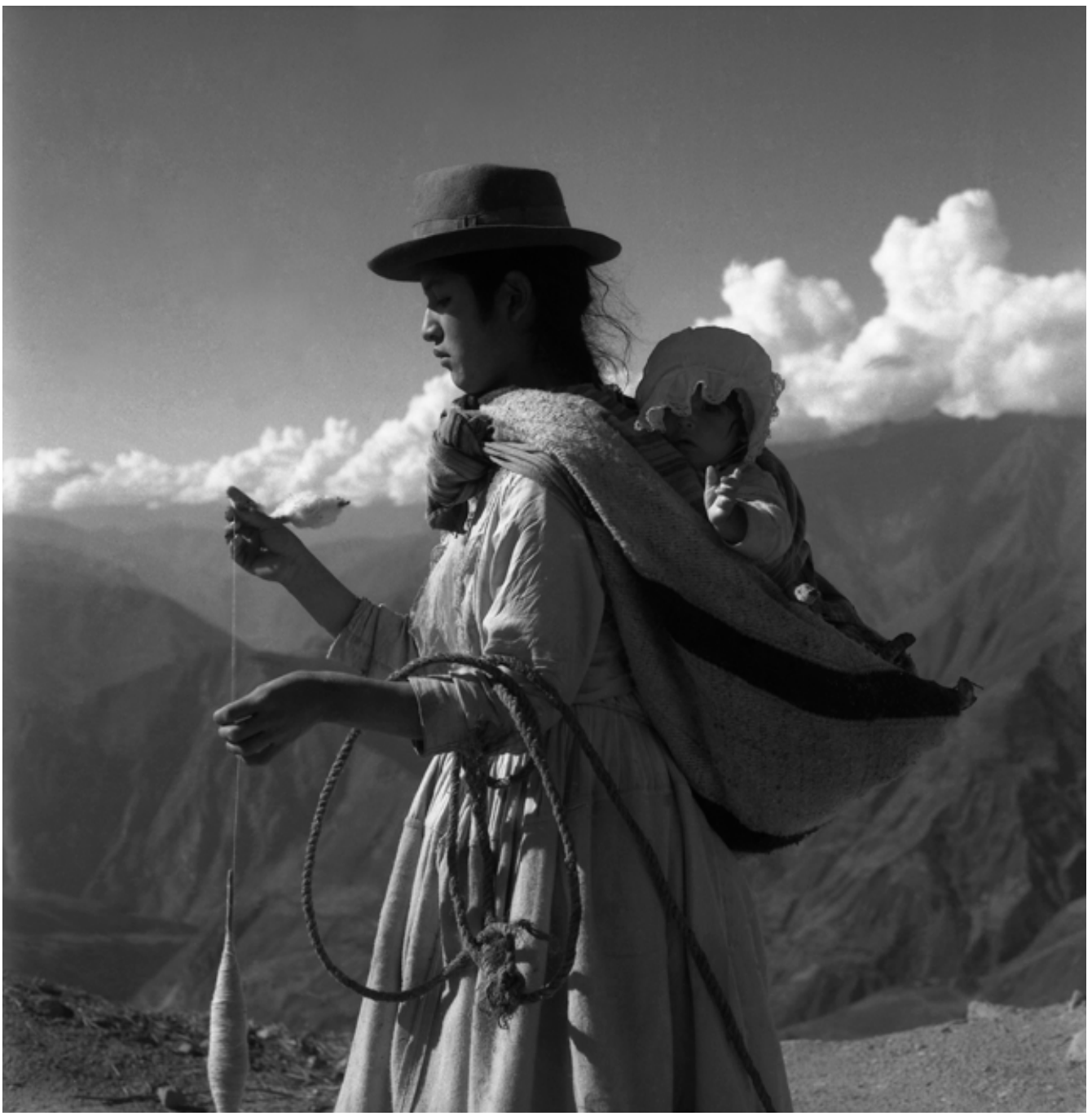

Alturas de Colcabamba, 1958 


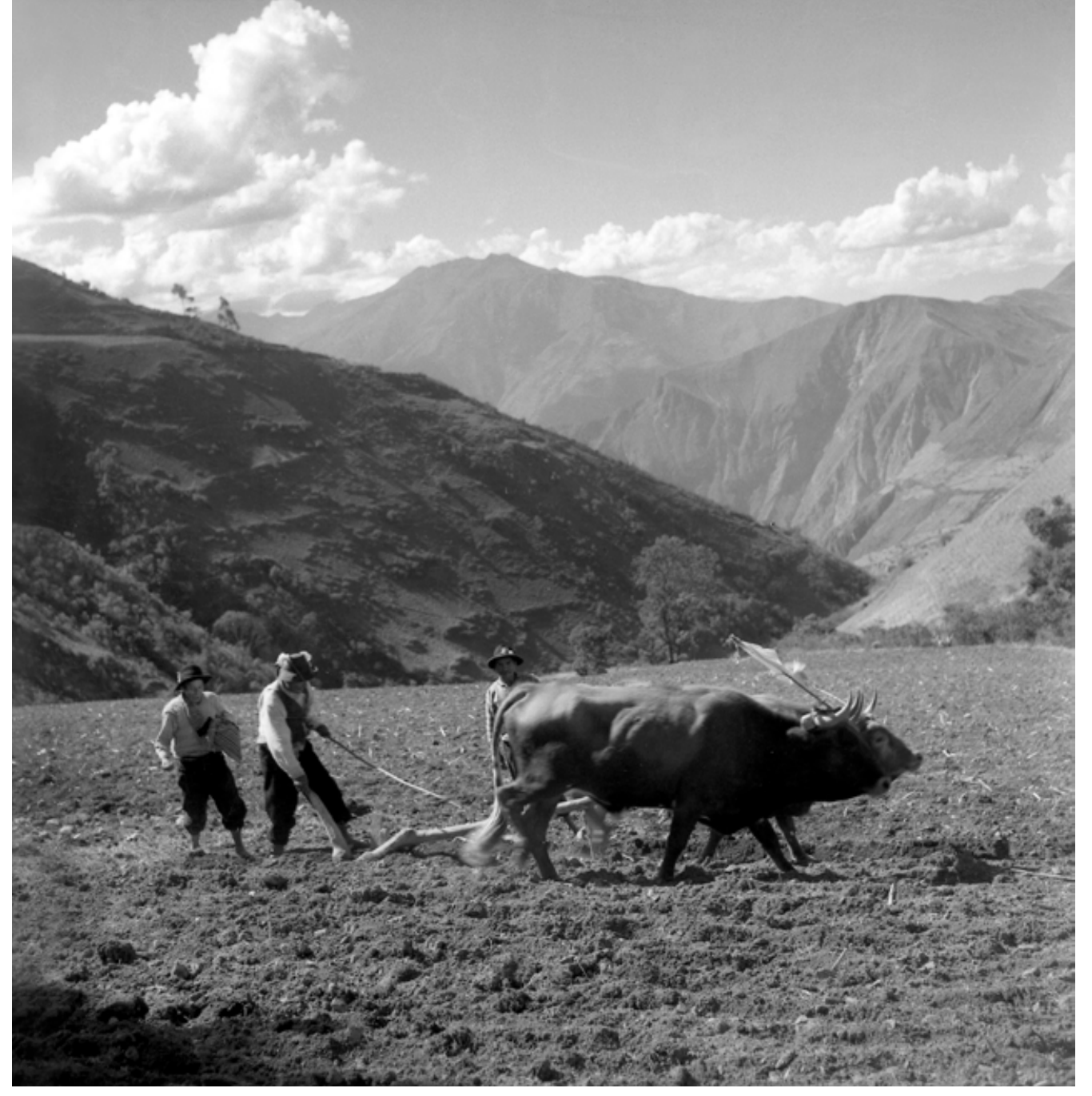

Arado. Colcobamba, 1958

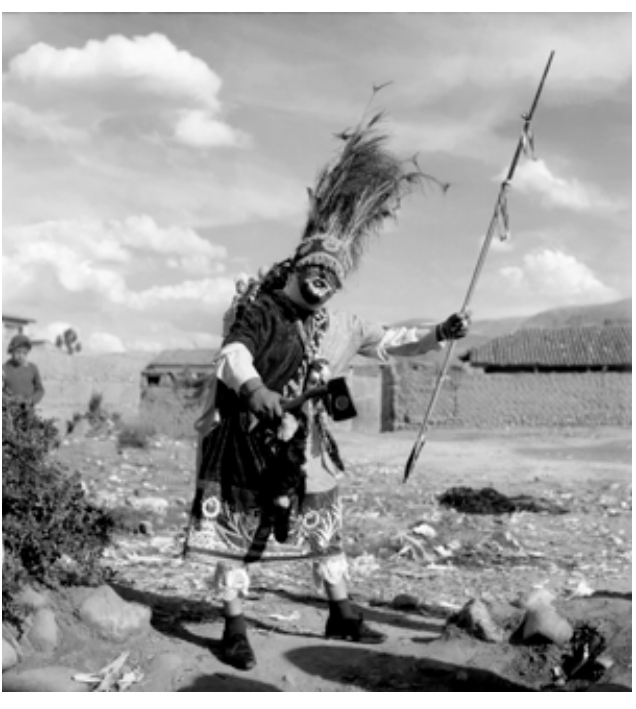

Danzande de Shapis. Chupaca, Huancayo, 1950.

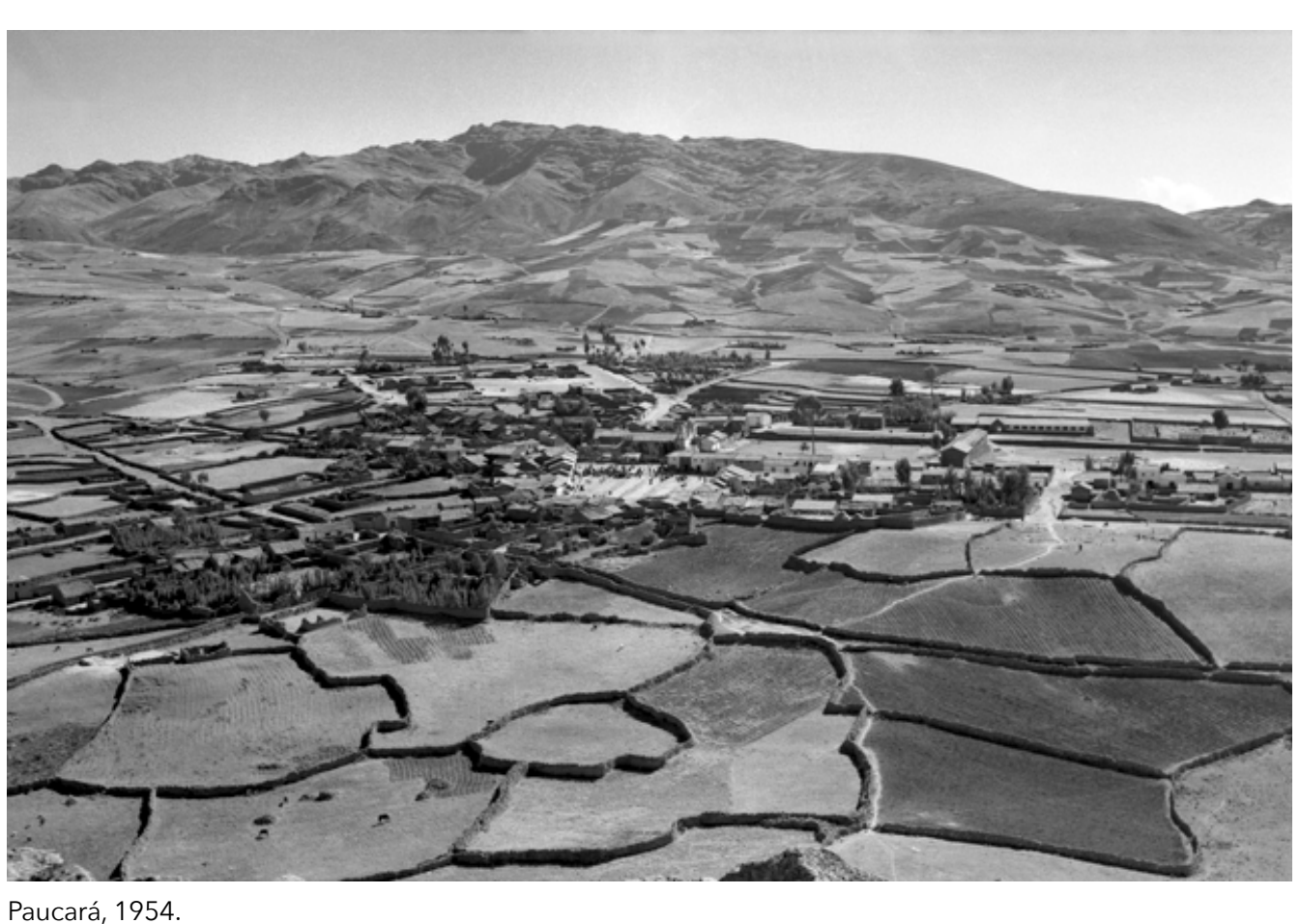




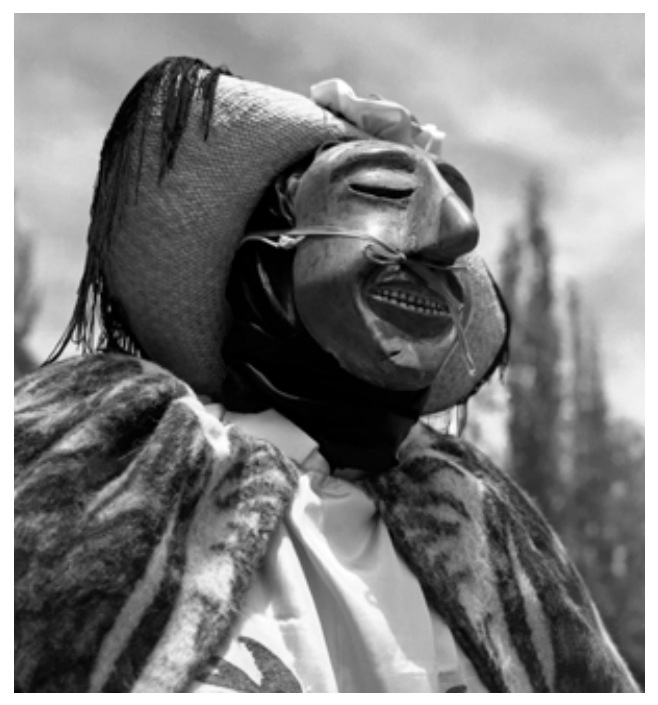

Huacón. Mito, 1960.

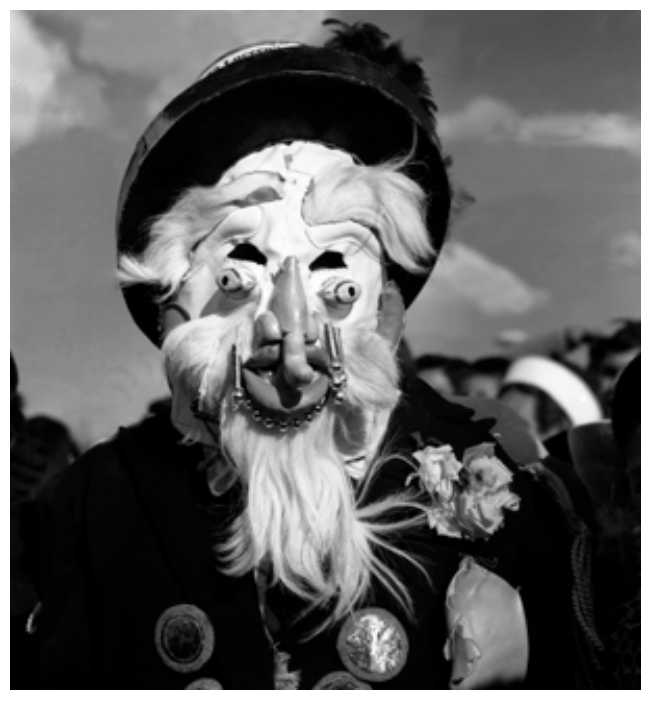

Máscara de Huatrilas. Jauja, 1961.

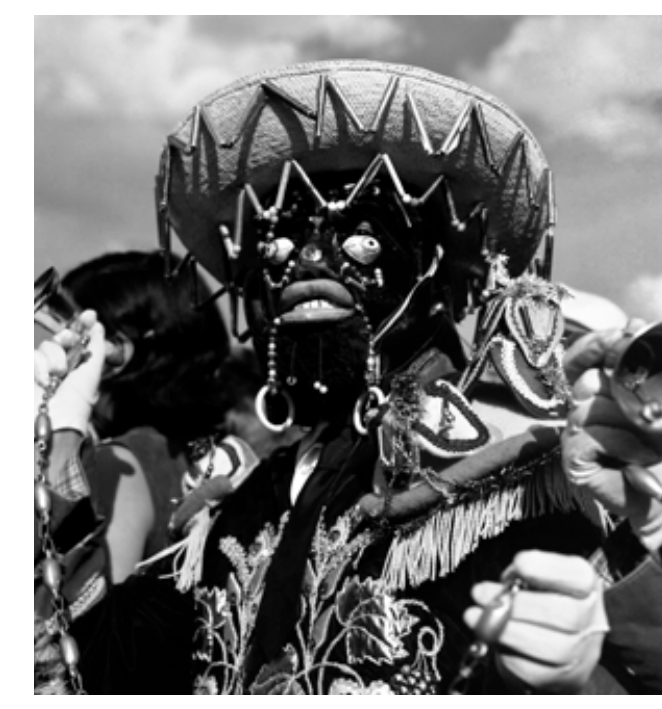

Negrito. Huánuco, 1949.

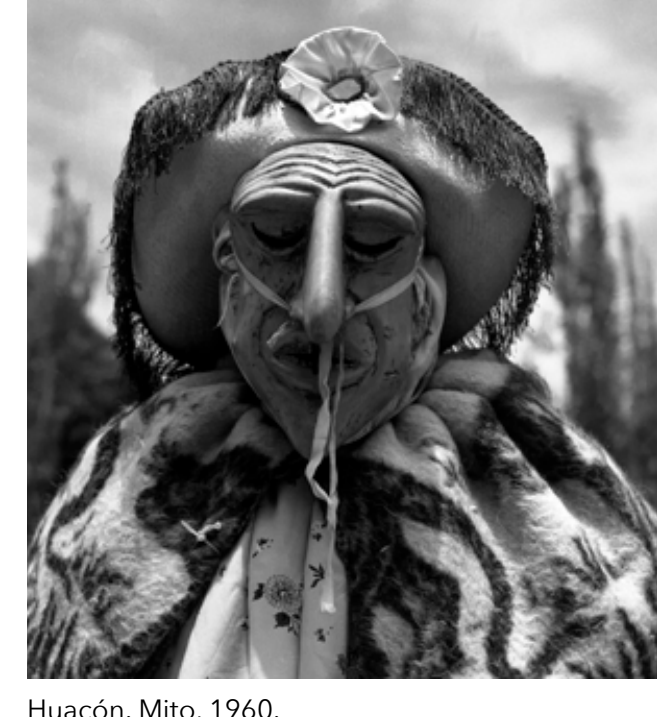

Huacón. Mito, 1960.

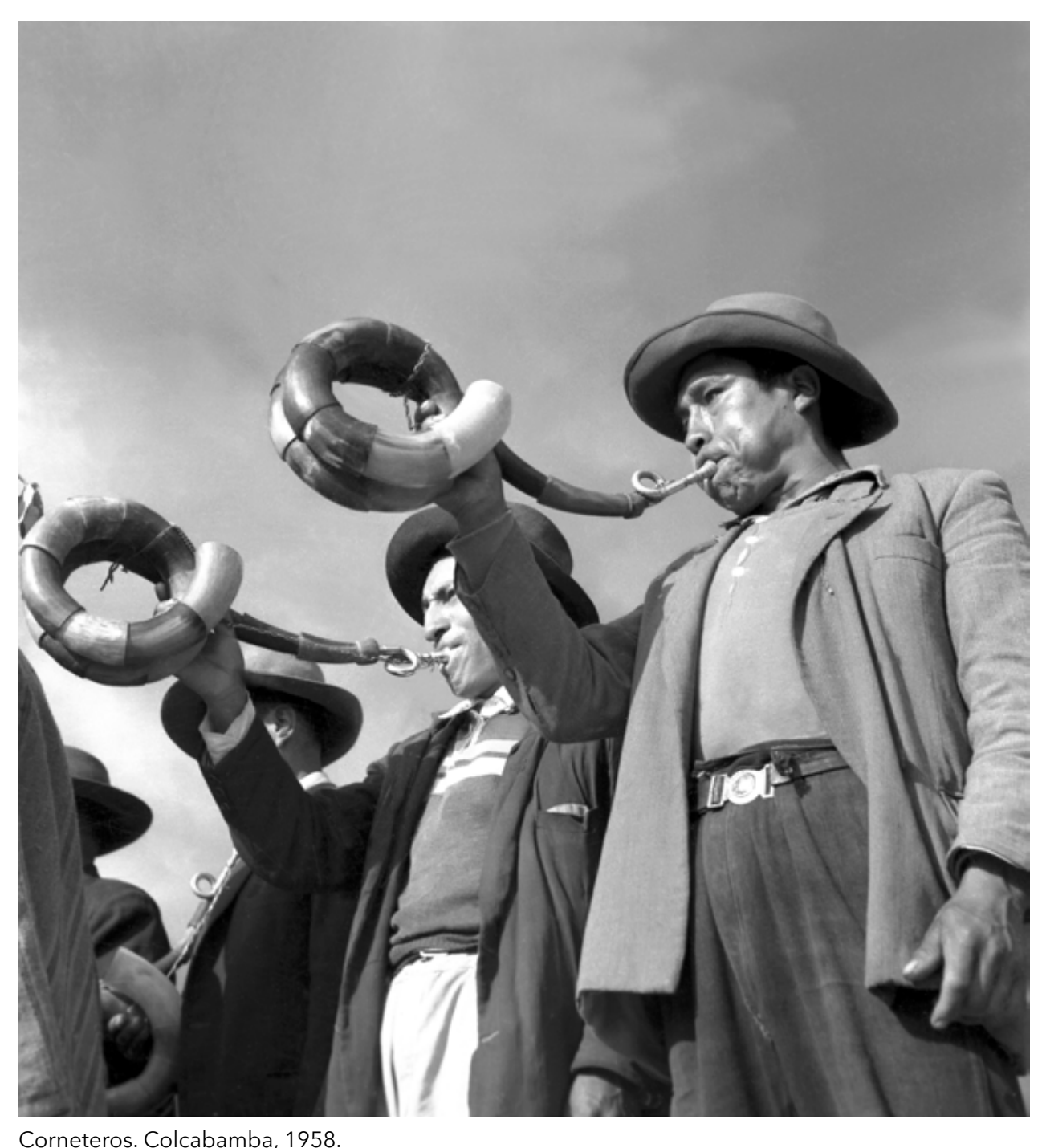



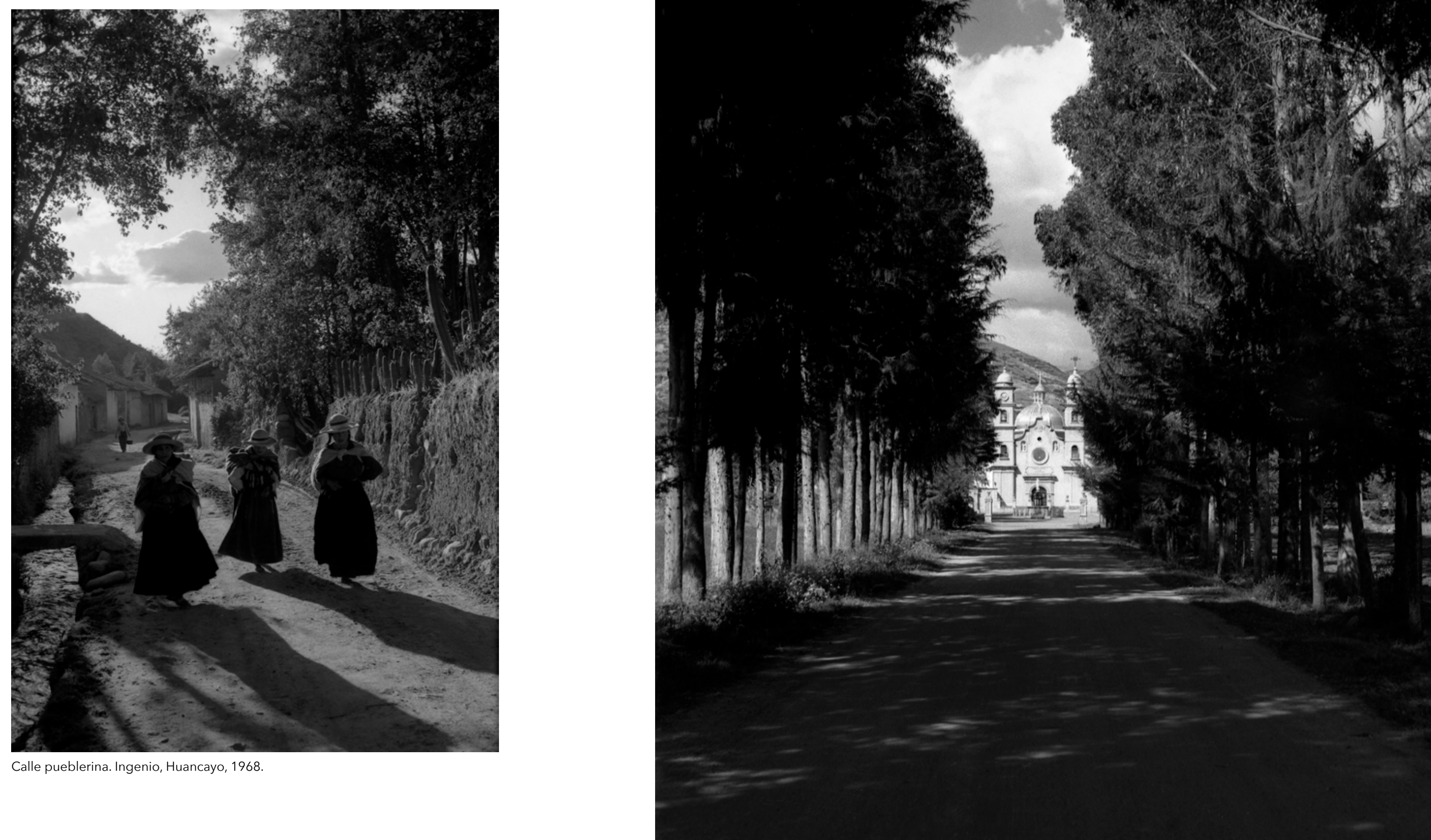